\title{
Flow over Broad Crested Weirs: Comparison of 2D and
} 3D Models

\author{
Shaymaa A. M. Al-Hashimi ${ }^{1}$, Huda M. Madhloom ${ }^{1,2}$, Rasul M. Khalaf ${ }^{1}$, Thameen N. Nahi ${ }^{1}$ and Nadhir A. \\ Al-Ansari ${ }^{2}$ \\ 1. Department of Civil Engineering, Al-Mustansiriayah University, Baghdad 1001, Iraq; \\ 2. Department of Civil, Environmental and Natural Resources Engineering, Lulea University of Technology, 97187 Lulea, Sweden
}

\begin{abstract}
The flow over broad-crested weirs was simulated by computational fluid dynamic model. The water surface profile over broad crested weir was measured in a laboratory model and validated using two and three dimensional Fluent programs. The Reynolds Averaged Navier-Stokes equations coupled with the turbulent standard $(k-\varepsilon)$ model and volume of fluid method were applied to estimate the water surface profile. The results of numerical model were compared with experimental results to evaluate the ability of model in describing the behaviour of water surface profile over the weir. The results indicated that the 3D required more time in comparison with 2D results and the flow over weir changed from subcritical flow at the upstream (U/S) face of weir to critical flow over the crest and to supercritical flow at downstream $(\mathrm{D} / \mathrm{S})$. A reasonable agreement was noticed between numerical results and experimental observations with mean error less than $2 \%$.
\end{abstract}

Key words: Broad-crested weir, discharge coefficient, subcritical flow, numerical CFD, Fluent.

\section{Notation}

\begin{tabular}{|l|l|}
\hline$B$ & Width of the weir (m) \\
\hline$C_{d}$ & The dimensionless coefficient of discharge (-) \\
\hline$\vec{F}$ & The body force (N) \\
\hline $\mathrm{g}$ & The gravitational acceleration $\left(\mathrm{ms}^{-2}\right)$ \\
\hline$h_{\text {exp. }}$ & The experimental head (m) \\
\hline$h_{\text {num. }}$ & The numerical head (m) \\
\hline$h_{0}$ & $\begin{array}{l}\text { The head over the U/S weir crest to the free } \\
\text { surface (m) }\end{array}$ \\
\hline$N$ & The total number of points (-) \\
\hline$p$ & The pressure (pa) \\
\hline$Q$ & The discharge (m $\left.\mathrm{s}^{-1}\right)$ \\
\hline$t$ & The time (sec) \\
\hline$u_{i, j}$ & The velocity in X and Y direction \\
\hline$\alpha_{a}$ & The volume fractions of air (-) \\
\hline$\alpha_{w}$ & The volume fractions of water (-) \\
\hline$\rho$ & The density (kgm $\left.{ }^{-3}\right)$ \\
\hline$\mu_{0}$ & The dynamic viscosity (pas) \\
\hline$\mu_{t}$ & The turbulence viscosity (pas) \\
\hline$G_{k}$ & The production of turbulent kinetic energy (-) \\
\hline$\sigma_{k}$ and $\sigma_{\varepsilon}$ & $\begin{array}{l}\text { Are the turbulent Prandtl Numbers for } k \text { and } \varepsilon \\
\text { respectively (-) }\end{array}$ \\
\hline & \\
\hline
\end{tabular}

Corresponding author: Nadhir A. Al-Ansari, professor; research fields: water resources and environment. E-mail: nadhir.alansari@1tu.se.

\section{Introduction}

The broad crested weirs are a hydraulic structures widely used for depth control and flow measurement in field and laboratory canals. The geometry described as a flat-crested structure with a length $(L)$ of crest large enough compared to the flow thickness over the crest of the weir. The crest is broad when the streamlines of the flow are parallel to the crest and the pressure distribution is hydrostatic [1]. The general shape of broad crested weir is shown in Fig. 1.

The discharge equation of the weir represented a function of the head over weir crest and the geometrical weir (Eq. (1)) [2]:

$$
Q=C_{d} \frac{2}{3} \sqrt{\frac{2}{3}} \mathrm{~g} \cdot\left(h_{0}\right)^{3 / 2} \cdot B
$$

where;

$Q$ is the discharge, $C_{d}$ is the dimensionless coefficient of discharge, $\mathrm{g}$ is the gravitational acceleration, $h_{0}$ is the head over the U/S weir crest to the free surface, and $B$ is the width of the weir. 


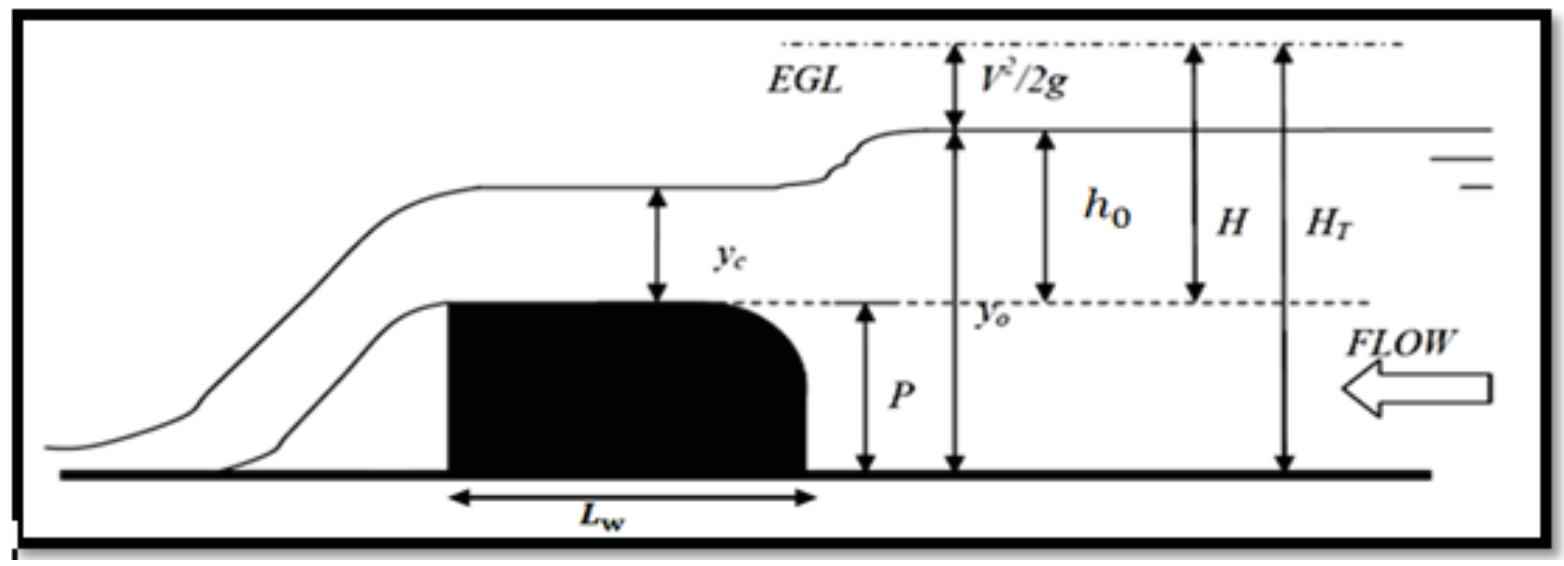

Fig. 1 Definition sketch of a broad-crested weir [3].

In recent years, the characteristic of flow over broad-crested weirs has been introduced by many researches. Sarker and Rhodes [4] used the simple geometry of the rectangular broad-crested weir to test one dimensional (1D) model of CFD (computational fluid dynamics) software with complex regions of separated flow that affects its hydrometric performance in open channel flows. The results indicated the upstream water depth was rapidly-varied flow profile over the crest for the given flow rate. Ramamurthy, Tim and Rao [5] showed that the characteristics of flow over broad-crested weirs with a square-edged and a round-nosed upstream corner vary with the ratios $H / L$ and $R / p$. The upstream head, $H$, the length $L$, the height $P$, and the radius, $R$. Experimental data are presented to validate the calculate results for the coefficient of discharge. Haun, Olsen and Feurich [6] calculated the water flow over a trapezoidal broad-crested weir using two CFD codes. Flow-3D used the VOF (volume of fluid) method with a fixed grid. SSIIM 2 used algorithm based on the continuity equation with an adaptive grid. The result showed the accuracy of the model depends on the grid size. Hager and Schwalt [7] recommended the broad-crested weir as a discharge measurement structure. It satisfies some standard conditions based on experimental investigation for surface profile, separation profile, bottom pressure profile, and velocity profile close to the upper crest corner. The broad-crested weir is characterized by insensitivity to tail water submergence. Al-Hashimi [8] studied the effect of inclination the U/S face of broad crested weirs from $90^{\circ}$ to $23^{\circ}$ using CFD model and laboratory data to increase the hydraulic performance of broad crested weirs by reducing the effect of flow separation. The results indicated that the efficiency of discharge was increased with slope of $23^{\circ}$ about $22 \%$ higher than the slope of $90^{\circ}$. The effect of the channel slope on the energy dissipation $(E \%)$ over single step broad crested weirs were simulated experimentally and numerically by using 2D CFD [9].

The objective of this paper was to determine how well CFD (Fluent Version 6.3) software could model the free-surface profile in 2D and 3D flow around the broad crested weir structure, with a view to its better for modeling. The CFD model was carried out in comparison with a physical model operated over broad crested weir in a rectangular laboratory flume.

\section{Physical Model}

The experimental works were conducted at the hydraulic laboratory of Al-Mustansiriayah University, Baghdad, Iraq. The experiments were carried out in a flume of $0.3 \mathrm{~m}$ deep, $0.3 \mathrm{~m}$ wide and $4.8 \mathrm{~m}$ long with the front side of glass (Fig. 2). A precise static point gauges $( \pm 0.1)$ were installed at the top of the centerline of a flume for measuring water level. Water flow was supplied from a storage tank that contains an 
electrical pump. The discharge was measured with flow meter. The model of the broad-crested weir was made of well-polished steel. The radius of curvature was designed to $0.03 \mathrm{~m}$ to reduce the effects of separations zone [9]. It was located at $0.9 \mathrm{~m}$ from the entrance of the flume to make the water surface levels stabile and uniform. The dimensions of the model were $0.15 \mathrm{~m}$ in height $(P), 0.3 \mathrm{~m}$ in width $(B)$ and $0.36 \mathrm{~m}$ in length $(L)$ as shown in Fig. 3. It was designed according to practical design recommendations that have been stated as limitation conditions of broad-crested weirs by ASTM International Designation [2] as:

$$
\begin{aligned}
& h_{0} \geq 0.06 \mathrm{~m} \text { or } \geq 0.05 L ; \\
& 0.05 \leq h_{0} / L \leq 0.57 ; \\
& h_{0} / P<1.5 ; \\
& P \geq 0.15 \mathrm{~m} ; \\
& B \geq 0.3 \mathrm{~m} \text { or } \geq h_{0} \text { or } \geq L / 5 ; \text { and } \\
& L \geq 1.75 h_{0} .
\end{aligned}
$$

\section{CFD Model Description}

Numerical modeling of weirs is very important in the engineering work and it can be used instead of physical modeling to save cost, effort and time due to the advances in computer technology [10]. CFD is a numerical tool that was used for simulating flow by applying Fluent software Version 6.3 to solve 2D and $3 \mathrm{D}$ problems in open channels.

The assumptions of flow over weirs which used to derive and solve using numerical techniques are fully turbulent, unsteady, incompressible, and non-viscous.

The differential equations used in Fluent software are continuity and RANS (Reynolds Averaged Navier-Stokes equations). These are based on the principles of conservation of mass and Newton's Second Law. These equations are described by Eqs. (2) and (3) [10]:

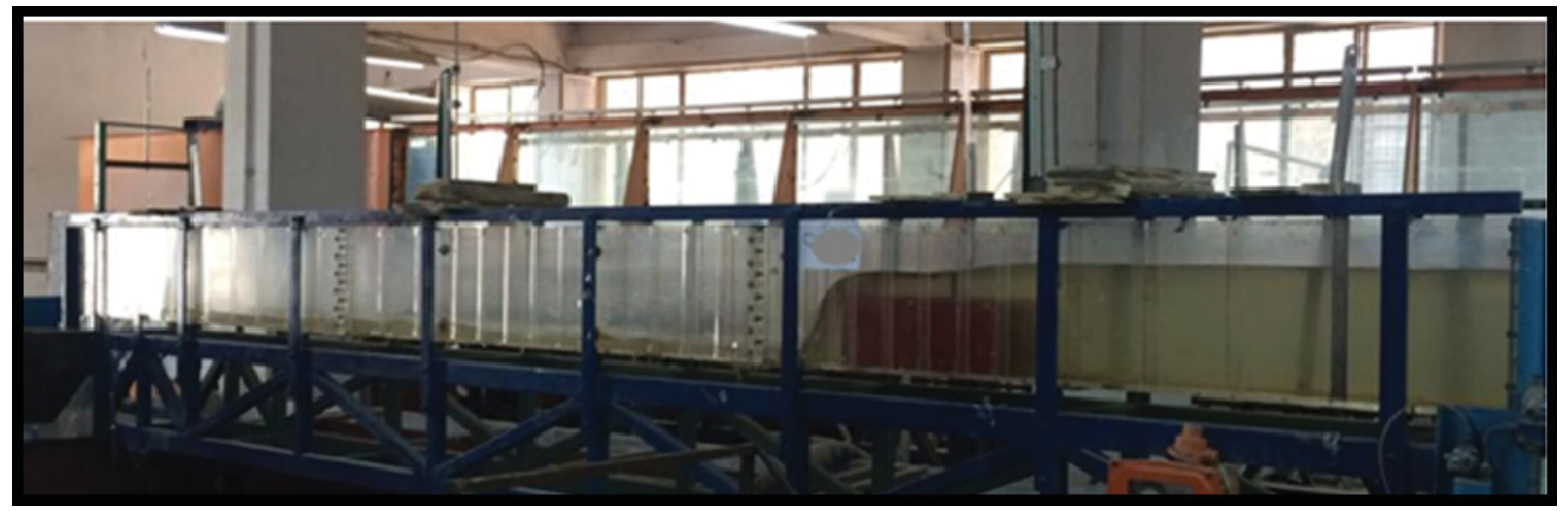

Fig. 2 Photograph showing the laboratory flume with broad crested weir.

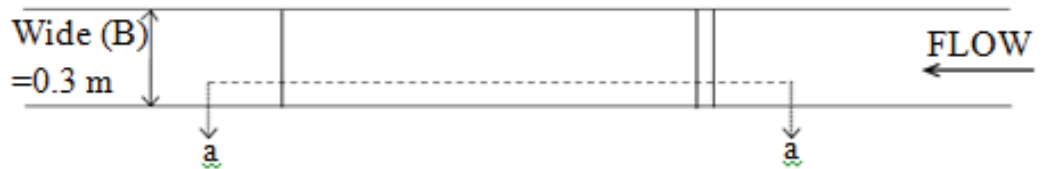

SEC. a-a

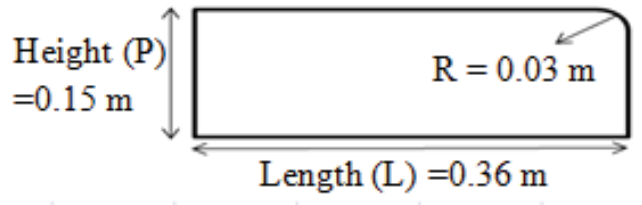

Fig. 3 Schematic of the broad-crested weir and related notation. 


$$
\begin{gathered}
\frac{\partial \rho}{\partial t}+\frac{\partial}{\partial x_{i}}\left(\rho u_{i}\right)=0 \\
\frac{\partial}{\partial t}\left(\rho u_{i}\right)+\frac{\partial}{\partial x_{i}}\left(\rho u_{i}\right)=-\frac{\partial P}{\partial x_{i}}+\frac{\partial}{\partial x_{i}}\left[\mu\left(\frac{\partial u_{i}}{\partial u_{j}}+\frac{\partial u_{j}}{\partial x_{i}}\right)\right]+\rho g_{i}+\vec{F}
\end{gathered}
$$

where, $\rho$ is the density, $u_{i, j}$ is the velocity in $\mathrm{X}$ and $\mathrm{Y}$ direction, $x$ is the space, $t$ is the time, $p$ is the pressure, $\mu=\mu_{0}+\mu_{t}, \mu_{t}$ is the turbulence viscosity and $\mu_{0}$ is the dynamic viscosity, $\vec{F}$ is the body force and $g_{i}$ is the acceleration.

The Fluent solves RANS equations with different turbulence models; Standard $k-\varepsilon$, renormalization group (RNG) $k-\varepsilon$, and realizable $k-\varepsilon$ [11]. In the present work, the standard $(k-\varepsilon)$ turbulence model was employed. It has two advantages; there is strong curvature in the streamlines and the accelerating flow over the weir. The mathematical equations which represent turbulent energy dissipation and turbulent kinetic energy rate are as follows [12]:

$$
\begin{gathered}
\frac{\partial}{\partial t}(\rho k)+\frac{\partial k}{\partial x_{i}}\left(\rho k u_{i}\right)=\frac{\partial}{\partial x_{j}}\left[\left(\mu+\frac{\mu_{t}}{\sigma_{k}}\right) \frac{\partial k}{\partial x_{i}}\right]+G_{k}-\rho \varepsilon \\
\frac{\partial}{\partial t}(\rho \varepsilon)+\frac{\partial \varepsilon}{\partial x_{i}}\left(\rho \varepsilon u_{i}\right)=\frac{\partial}{\partial x_{j}}\left[\left(\mu+\frac{\mu_{t}}{\sigma_{\varepsilon}}\right) \frac{\partial \varepsilon}{\partial x_{i}}\right]+G_{1 \varepsilon} \frac{\varepsilon}{k} G_{k}-G_{2 \varepsilon} \rho \frac{\varepsilon^{2}}{k}
\end{gathered}
$$

where, the eddy viscosity $\mu_{t}$ is:

$$
\mu_{t}=C_{\mu} \rho \frac{k^{2}}{\varepsilon}
$$

$G_{k}$ is the production of turbulent kinetic energy. $G_{1 \varepsilon}$, $G_{2 \varepsilon}$ and $C_{\mu}$ are constants and equal to $1.44,1.92$, and 0.09, respectively. $\sigma_{k}$ and $\sigma_{\varepsilon}$ are the turbulent Prandtl numbers for $k$ and $\varepsilon$ equal to 1.0 and 1.3, respectively.

VOF is one of the methods which can be used to determine the water surface profile that represents the sharp interface between the water and air phases. VOF is the holds in the absence of any inter-phase mass transfer. When the program models the free surface between water and air, a transport equation is solved for the water phase [13]:

$$
\frac{\partial \alpha_{w}}{\partial t}+\frac{\partial}{\partial x_{i}}\left(\alpha_{w} u_{i}\right)=0
$$

Only one such transport equation needs to be solved since the volume fraction of the other phase can be inferred from the constraint:

$$
\alpha_{a}=1-\alpha_{w}
$$

where, $\alpha_{w}$ and $\alpha_{a}$ are the volume fractions of water and air, respectively.

The flow domain is divided into a grid consisting of many numbers of cells. In each cell, if it contains only air, then $\alpha_{w}=0$, when it contains only water, then $\alpha_{w}$ $=1$ and if it is contains air and water, $0 \leq \alpha_{w} \leq 1$. According to the local volume fraction, the flow properties in each cell are adjusted. The general shape of the model with volume fraction is shown in Fig. 4.

\section{Geometry and Boundary Conditions}

The first step in numerical model is generating a mesh for the board crested weir having the same dimension of the experimental work. The mesh size used in CFD can have an important effect on the simulation time and accuracy of the result. Gambit program was used to apply geometries and meshes. Fig. 5 shows the geometrical mesh of the weir in 2D and Fig. 6 shows the geometrical mesh of the weir in 


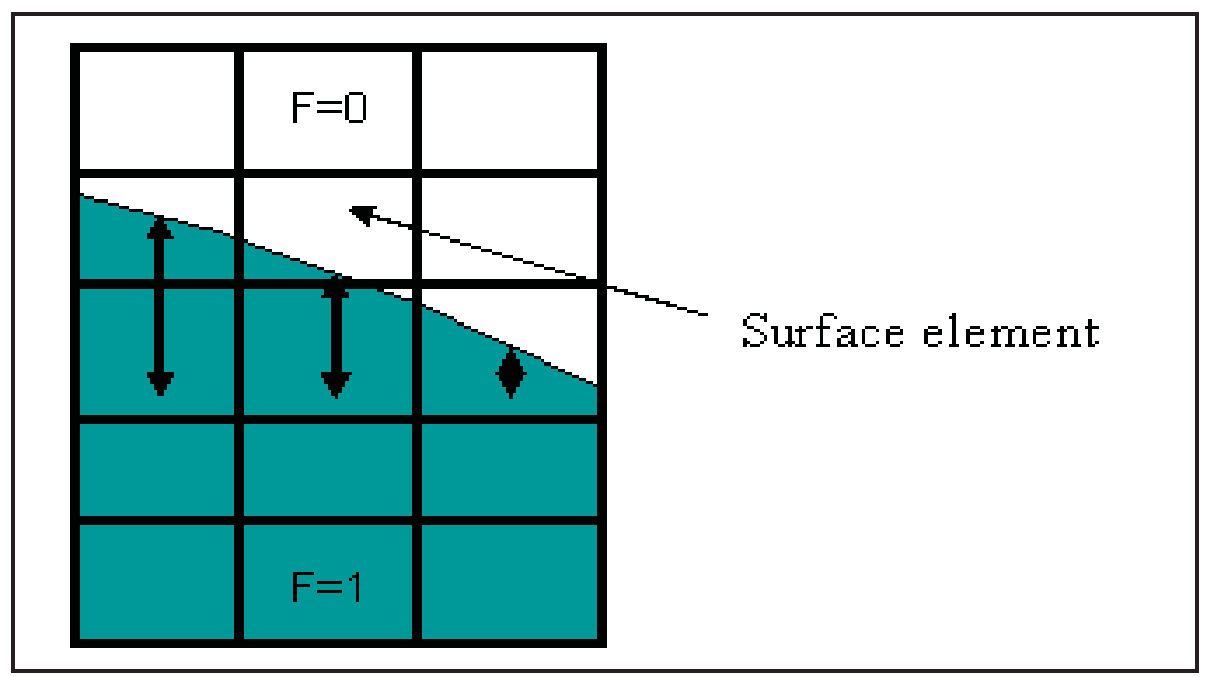

Fig. 4 General shape of mesh in volume of fluid method.

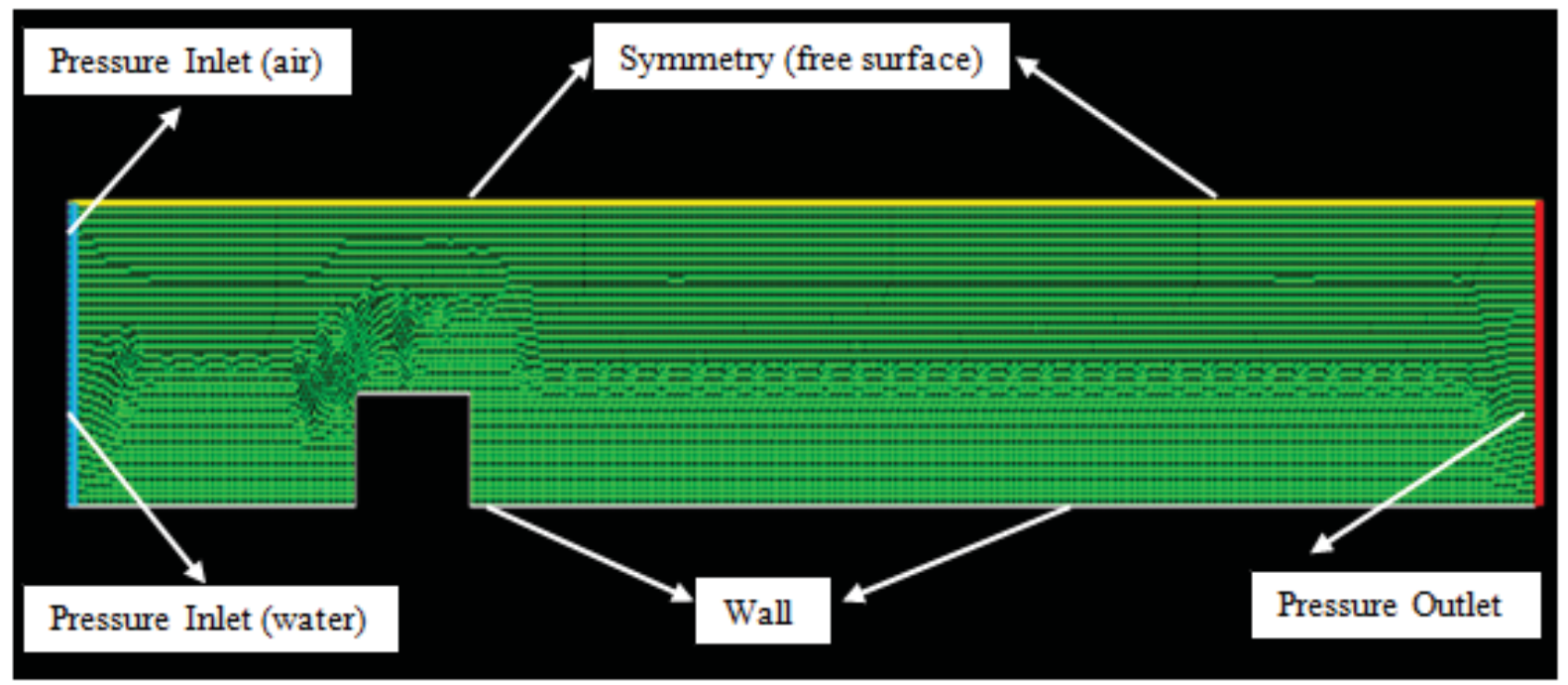

Fig. 5 Mesh and boundary conditions of 2D broad crested weir using Gambit program.

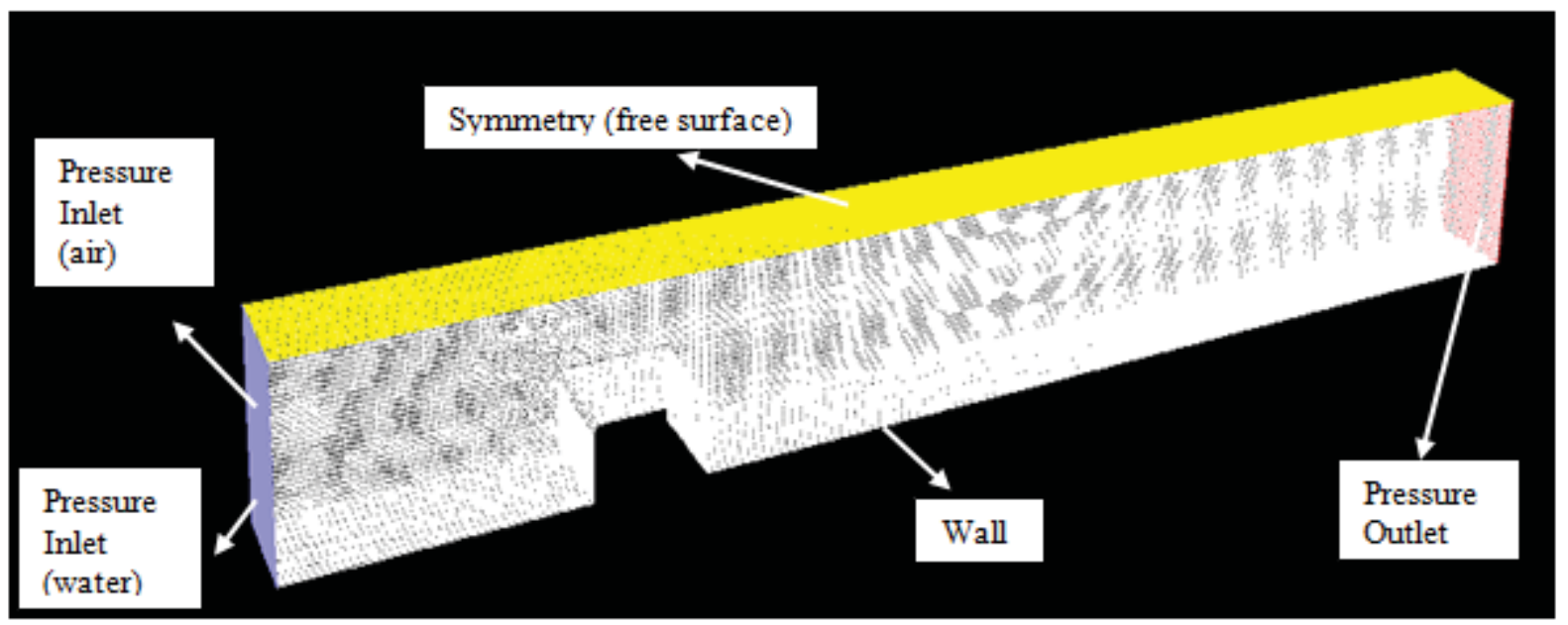

Fig. 6 Mesh and boundary conditions of 3D broad crested weir using Gambit program. 
3D. The cell sizes around the upstream corner of the wire are reduced which consisted of 22,962 quadrilateral cells. The cell size around the downstream corner of the weir crest increases gradually with distance from the walls. The open channel boundary conditions were applied to the CFD model pressure inlet at the main channel inlet, the symmetry at the boundaries which are open to the atmosphere, the pressure outlet at the main channel outlet. Also wall boundary was used to specify the solid surfaces. The pressure inlet boundary condition represents an option which ensures easy description of the bottom and the surface water levels of the main channel and also the velocity of the channel flow. The boundary conditions of for $2 \mathrm{D}$ and $3 \mathrm{D}$ used in this study are shown in Figs. 5 and 6.

\section{Results and Discussion}

A broad crested weir has been simulated using Fluent in 2D and 3D to test the accuracy of the results for water surface profile. The numerical results were compared with the experimental results in XY plot in Fig. 7, where, $\mathrm{X}$ is the length of the flume and $\mathrm{Y}$ is the depth of flow. The results showed in $2 \mathrm{D}$ and $3 \mathrm{D}$ that the depth of flow level was nearly stable till $(0.7 \mathrm{~m})$ from the inlet of the flume. The depth of flow start decreased at the U/S edge of the broad crested weir and continues in decrease to the $\mathrm{D} / \mathrm{S}$ edge of the weir. The flow condition was subcritical flow at U/S edge, critical flow at weir crest, and supercritical flow at $\mathrm{D} / \mathrm{S}$ edge in both simulation $2 \mathrm{D}$ and $3 \mathrm{D}$.

The water surface profile, velocity vectors and pressure distribution over weir in $2 \mathrm{D}$ and $3 \mathrm{D}$ are shown in Figs. 8-13, respectively. It can be seen that there is a similar behavior for the distribution of the velocity and water surface profile over the weir in both 2D and 3D simulation with simple differences. The values of pressure are approximately the same for both 2D and 3D simulation.

\section{Sensitivity Analysis}

The RE (relative error) percentage, RMSE (root mean square errors) and MAE (mean absolute errors) were used to evaluate the accuracy of results for water surface profile.

The RE, RMSE and MAE are defined as [14]:

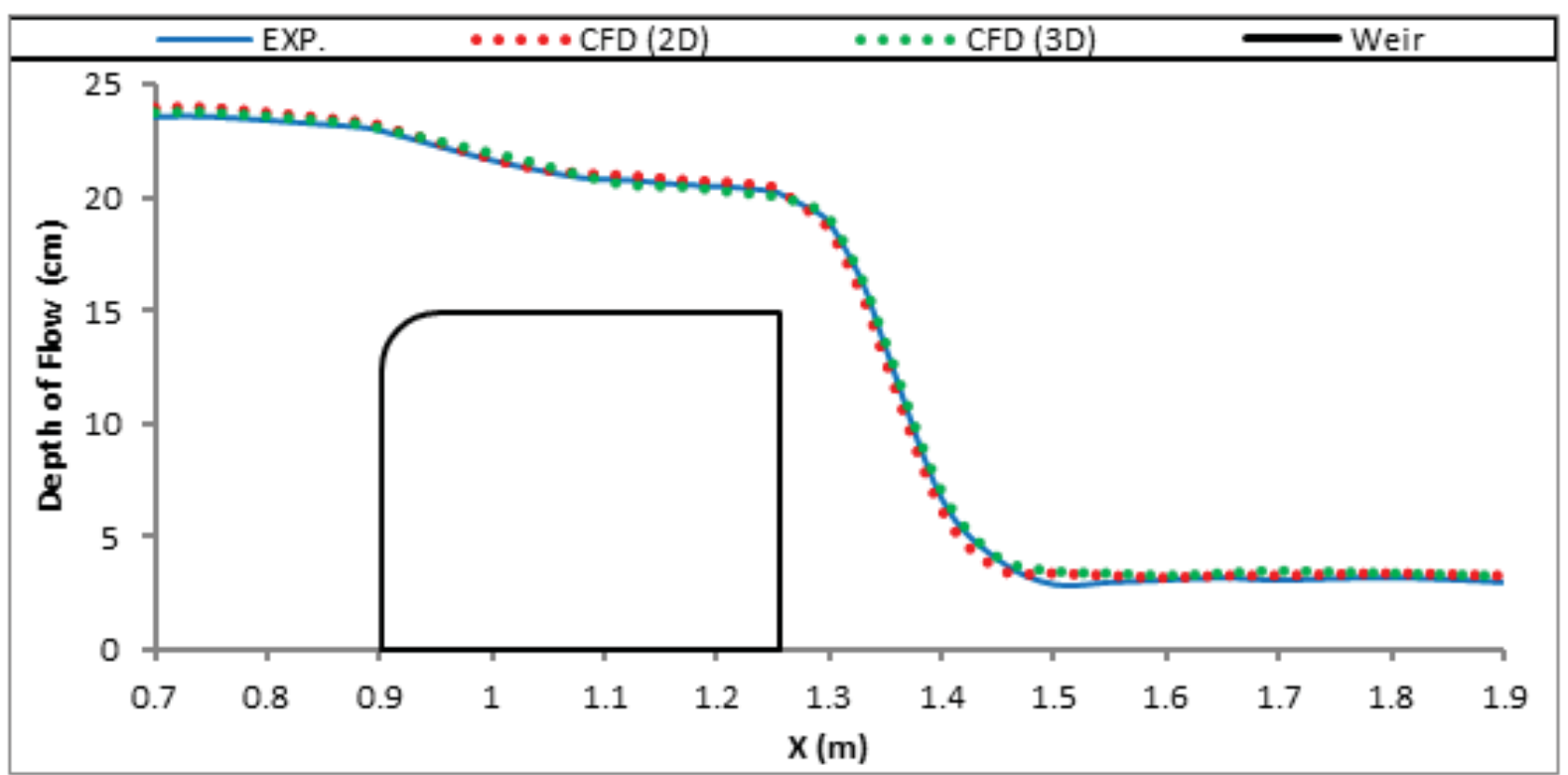

Fig. 7 Water surface profiles over weir. 


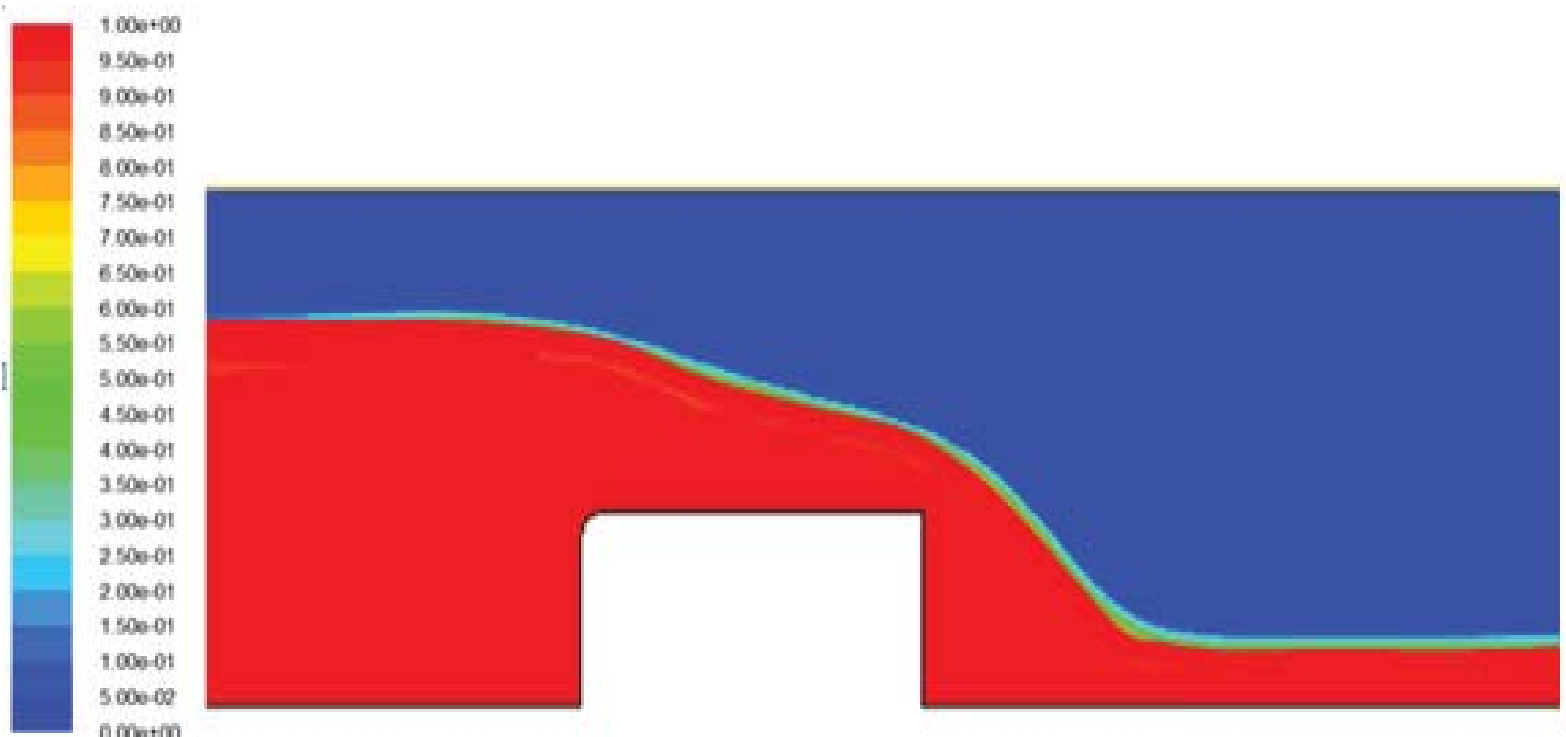

Fig. 8 . Free surface profiles over weir in 2D simulation.
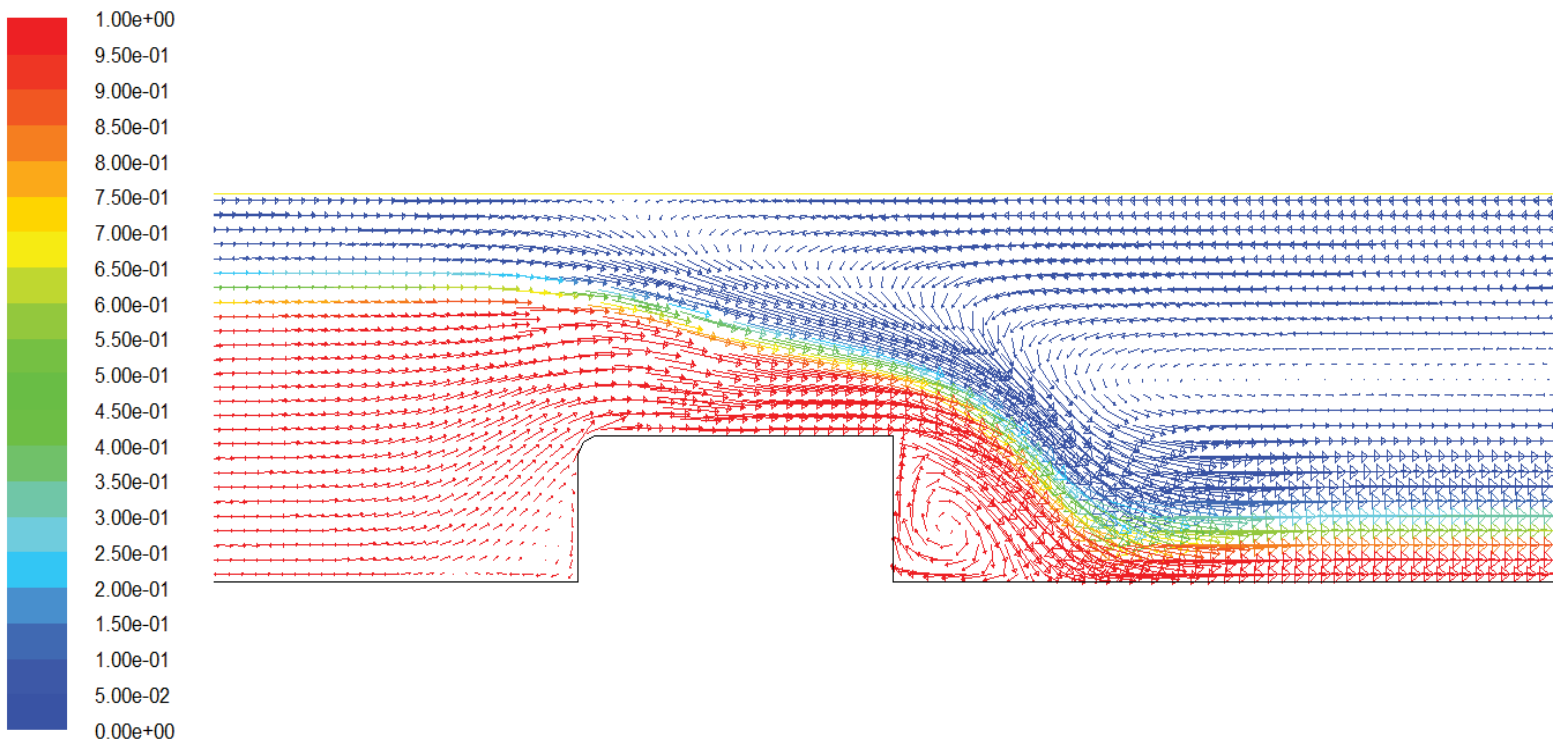

$5.00 \mathrm{e}-02$

$0.00 \mathrm{e}+00$

Fig. 9 Velocity distribution vectors over weir in 2D simulation. 

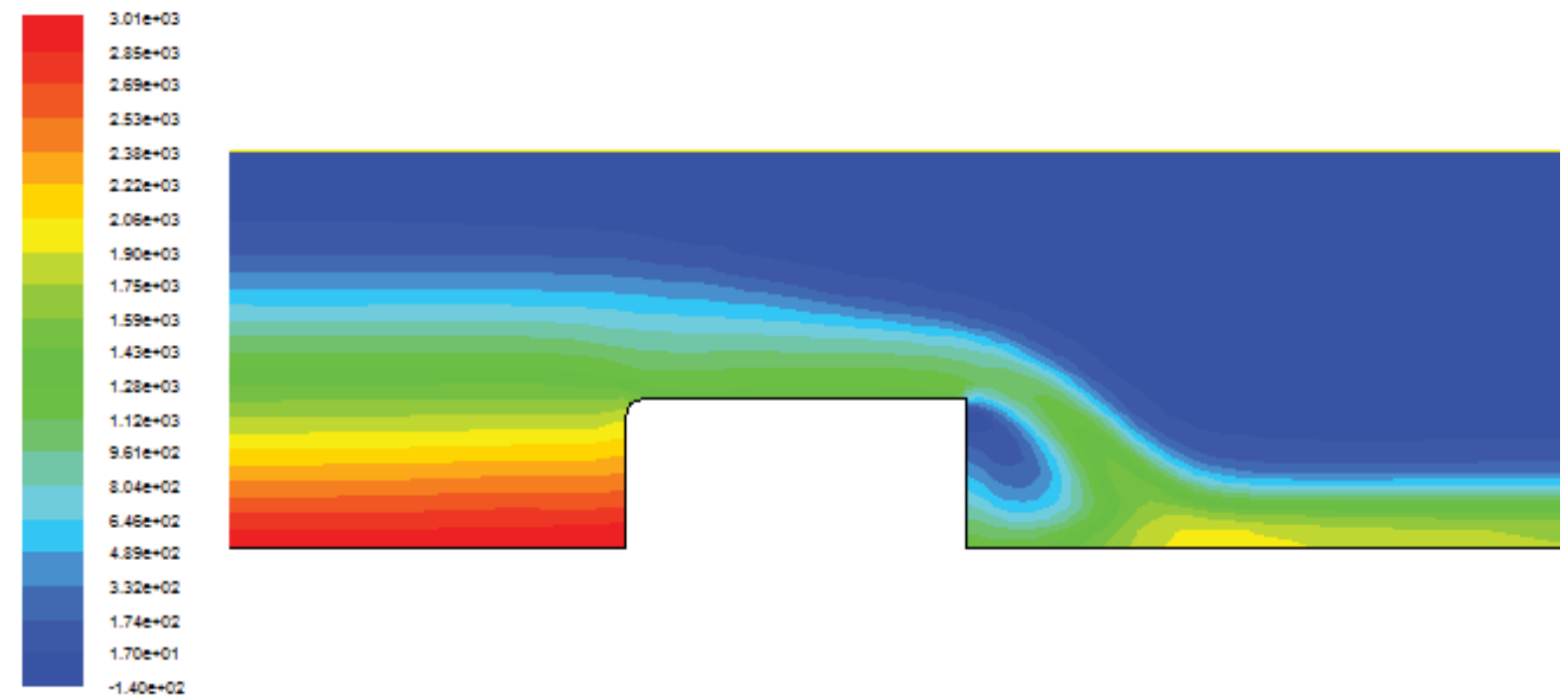

$1.742 \cdot 02$

$-1.40 \div \cdot 02$

Fig. 10 Distribution of pressure over weir in 2D simulation.
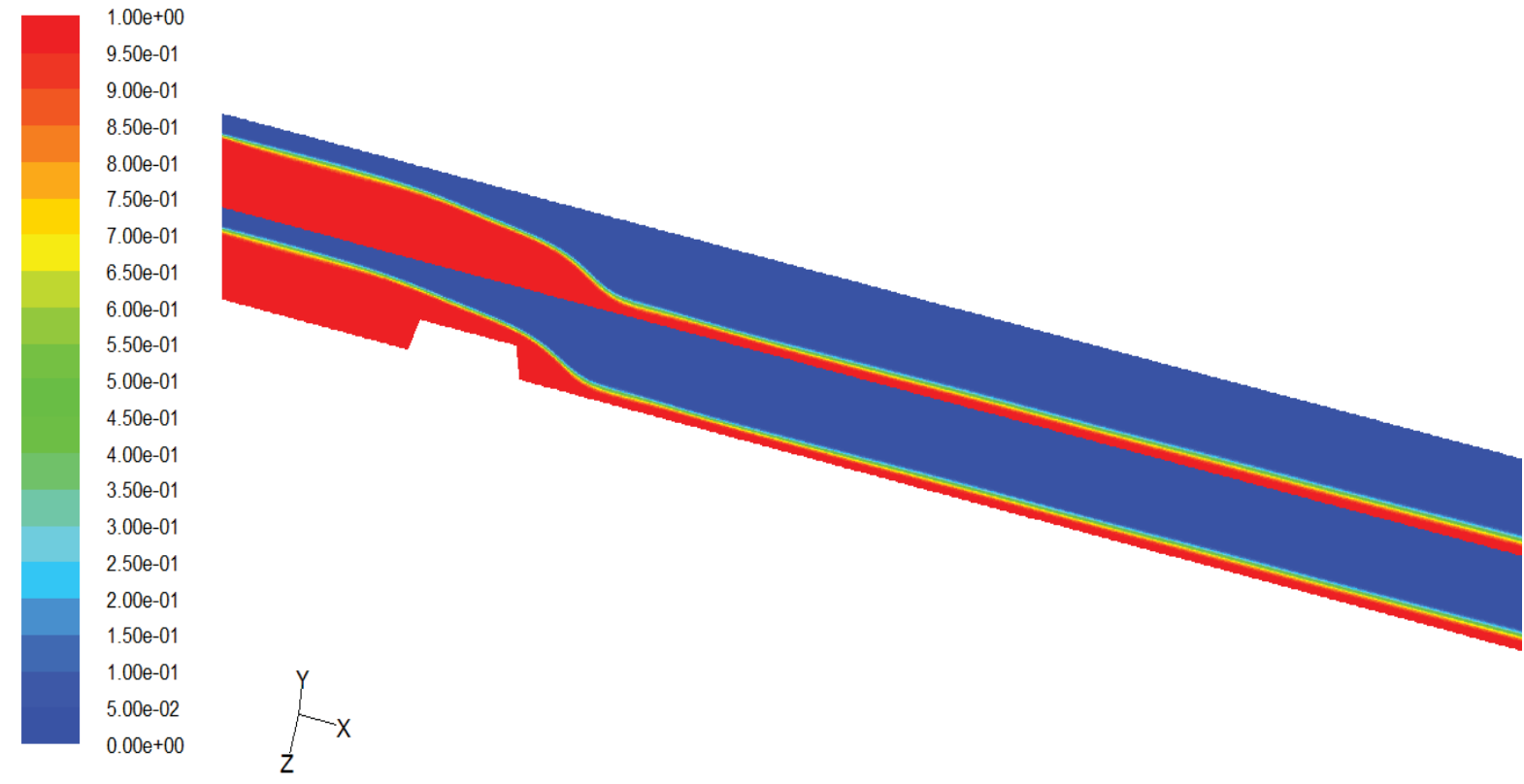

Contours of Volume fraction (water) (Time $=9.0400 \mathrm{e}+01$ )

Fig. 11 Free surface profiles over weir in 3D simulation. 


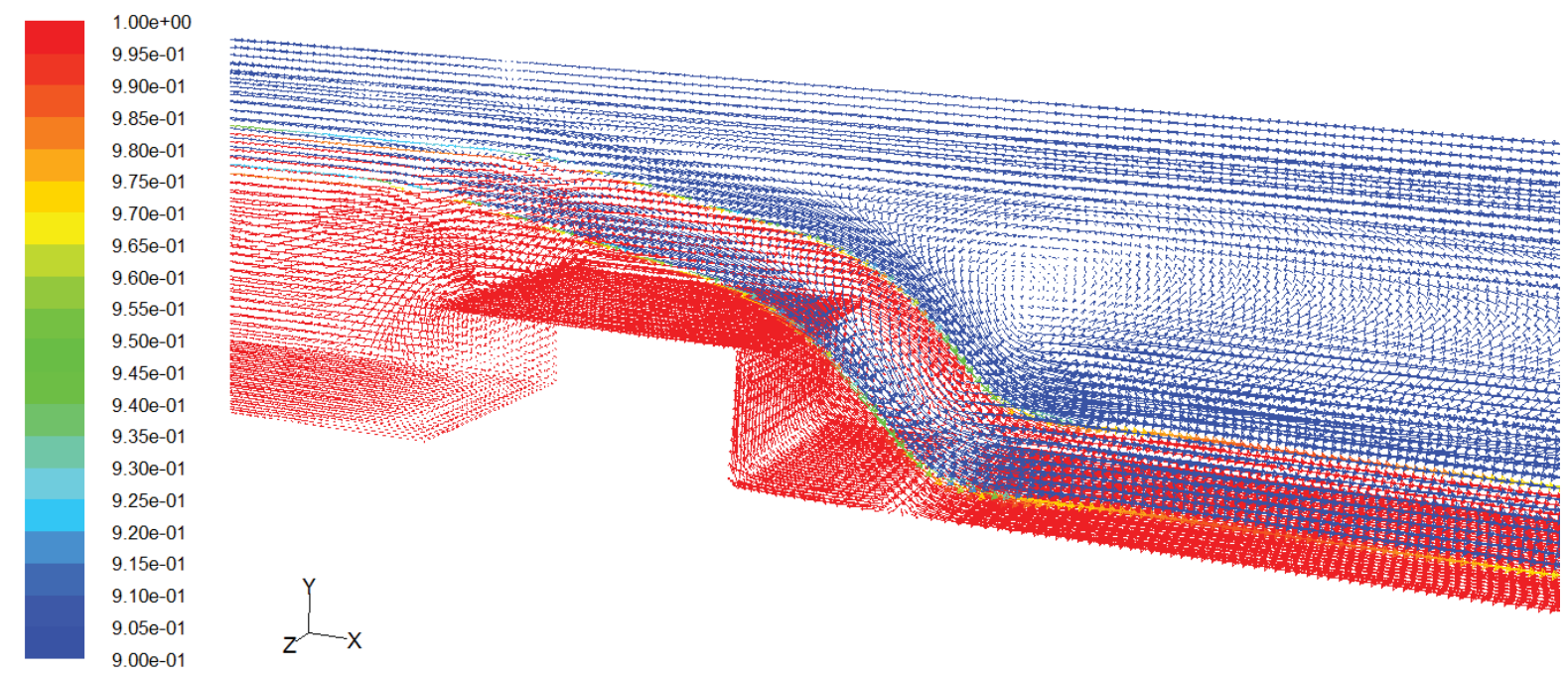

Fig. 12 Velocity distribution vectors over weir in 3D simulation.

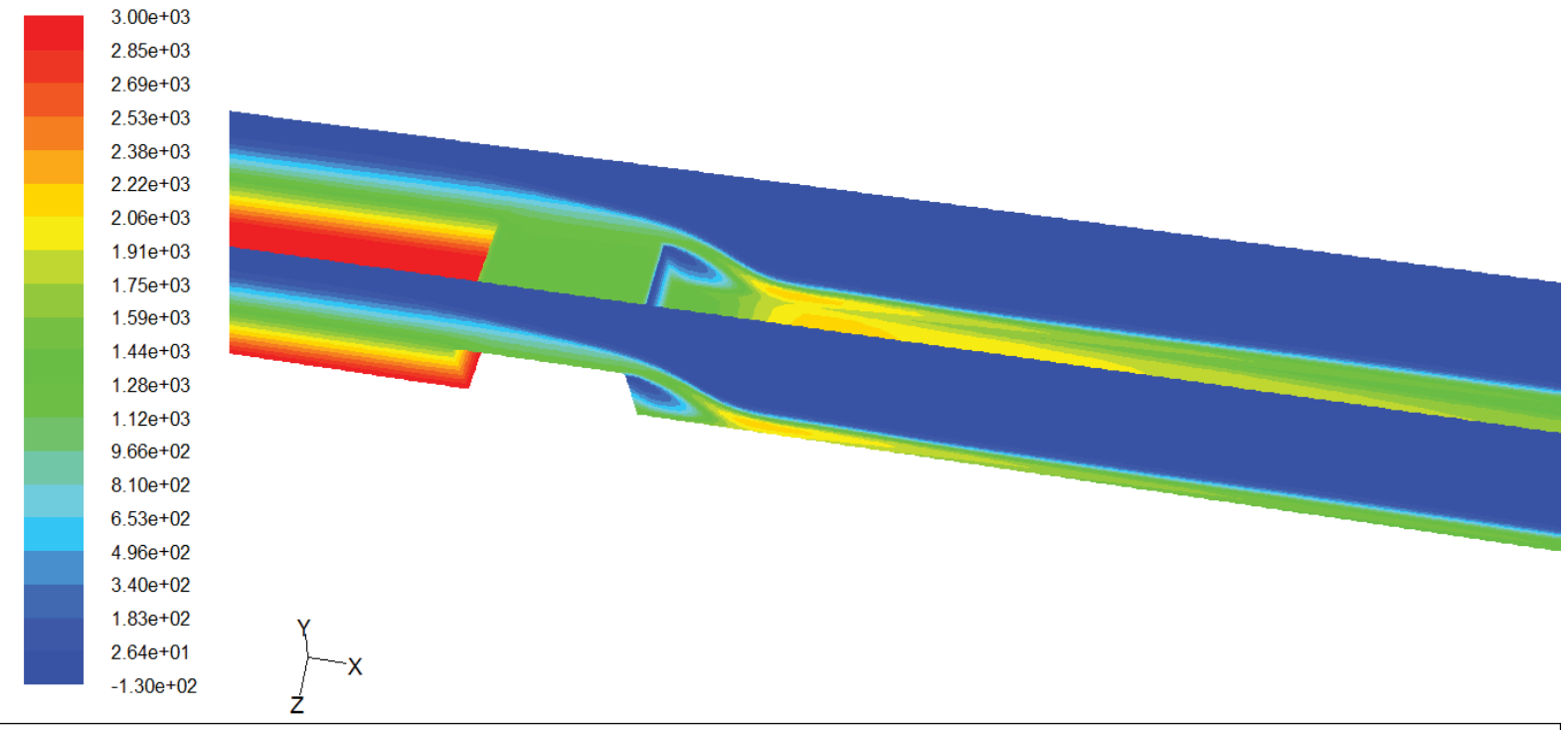

Contours of Total Pressure (mixture) (pascal) $($ Time $=9.0400 \mathrm{e}+01)$

Nov 01, 2016

FLUENT 6.3 (3d, dp, pbns, vof, ske, unsteady)

Fig. 13 Distribution of pressure over weir in 3D simulation.

Table 1 Relative error between numerical and experimental results at $x=0.7 \mathrm{~m}$.

\begin{tabular}{lll}
\hline Model work & $2 \mathrm{D}$ & $3 \mathrm{D}$ \\
\cline { 2 - 3 } & $C F D$ & $C F D$ \\
\hline$H_{\text {exp. }}(\mathrm{cm})$ & 23.6 & 23.6 \\
$H_{\text {num. }}(\mathrm{cm})$ & 24.2 & 24.1 \\
$R E \%$ & 2.5 & 2.1 \\
$R M S E \%$ & 0.6 & 0.5 \\
MAE\% & 0.6 & 0.5 \\
\hline
\end{tabular}




$$
\begin{gathered}
R E=\frac{100}{N} \sum_{i=1}^{N}\left|\frac{h_{\text {exp. }}-h_{\text {num. }}}{h_{\text {exp. }}}\right| \\
R M S E=\sqrt{\frac{1}{N} \sum_{i=1}^{N}\left(h_{\text {exp. }}-h_{\text {num. }}\right)^{2}} \\
M A E=\frac{1}{N} \sum_{i=1}^{N}\left|h_{\text {exp. }}-h_{\text {num. }}\right|
\end{gathered}
$$

where, $h_{\text {exp. }}$ is the experimental head; $h_{\text {mum }}$ is the numerical head; $N$ is the total number of points; and $i$ is the number of points.

Table 1 shows a good agreement between the experimental and numerical results at $x=0.7 \mathrm{~m}$. The percent of error between experimental and 2D numerical model was 2.5, 0.6 and 0.6 in $R E \%$, $R M S E \%$ and $M A E \%$, respectively. While, the percent of error between experimental and numerical model for 3D simulation was 2.1, 0.5 and 0.5 in $R E \%$, $R M S E \%$ and $M A E \%$, respectively.

The error percentage between $2 \mathrm{D}$ and $3 \mathrm{D}$ is very small. So we can consider that $2 \mathrm{D}$ and $3 \mathrm{D}$ give the same results. The simulation time of $3 \mathrm{D}$ is much longer than 2D under the same conditions. Therefore, 2D can be applied to solve the difficult fluid problem with good accuracy.

\section{Conclusions}

The Fluent with VOF method and standard $(k-\varepsilon)$ turbulence model were used to discusses the accuracy of $2 \mathrm{D}$ and $3 \mathrm{D}$ to predict the important flow variables over abroad crested weir.

By using experimental data as validation data, it is possible to build mathematical model with acceptable levels. The simulation results of $2 \mathrm{D}$ and $3 \mathrm{D}$ have a good agreement with experimental work. The most important findings were:

- The results showed that the water level is approximately stable until $x=0.7 \mathrm{~m}$ from the inlet of the flume and the flow variation from subcritical flow at the U/S of weir to critical flow over crest, then the flow became supercritical at $\mathrm{D} / \mathrm{S}$;
- The relative errors of water level at point $x=0.7$ $\mathrm{m}$ for broad crested weir between experimental and 2D result were 2.5, 0.6 and 0.6 in $R E \%, R M S E \%$ and $M A E \%$, respectively. While the relative error values between experimental and 3D numerical models were 2.1, 0.5 and 0.5 in $R E \%, R M S E \%$ and $M A E \%$, respectively;

- The 3D results have values approximately close to the $2 \mathrm{D}$ results but with longer simulation time. The numerical model proved that 2D model can be used to investigate the behavior of water surface profile over a weir in reasonable time and it will be less expensive. This work can be used in future for designing weirs without conducting laboratory tests to study the overtopping of other hydraulic structure such as dams.

\section{Acknowledgments}

The authors would like to thank Al-Mustansiriyah University, Baghdad, Iraq (www.uomustansiriyah.edu.iq) Baghdad-Iraq, where the experiments were carried out at the labs of the university and Lulea University of Technology for its support in the present work.

\section{Refrences}

[1] Chow, V. T. 1959. Open Channel Hydraulics. New York: McGraw-Hill.

[2] ASTM International Designation. 2014. Standard Guide for Selection of Weirs and Flumes for Open-Channel Flow Measurement of Water. United States.

[3] Hoseini, S. H., and Afshar, H. 2014. "Flow over a Broad-Crested Weir in Subcritical Flow Conditions, Physical Study." Journal of River Engineering 2: 1-35.

[4] Sarker, M. A., and Rhodes, D. G. 2004. "Calculation of Free-Surface Profile over a Rectangular Broad-Crested Weir." Flow Measurement and Instrumentation 15 (4): 215-9.

[5] Ramamurthy, A. S., Tim, U. S., and Rao, M. J. 1988. "Characteristics of Square-Edged and Round-Nosed Broad-Crested Weirs." Journal of Irrigation and Drainage Engineering 114: 61-73.

[6] Haun, S., Olsen, N. R. B., and Feurich, R. 2011. "Numerical Modeling of Flow over Trapezoidal Broad-Crested Weir." Engineering Applications of Computational Fluid Mechanics 5 (3): 397-405. 
[7] Hager, W. H., and Schwalt, M. 1994. "Broad-Crested Weir." Journal of Irrigation and Drainage Engineering 120 (1): 13-26. Accesed November 8, 2017. https://doi.org/10.1061/(ASCE)0733-9437(1994)120:1(13)

[8] Al-Hashimi, A. S., Sadeq, A., and Huda, M. 2015. "Determination of Discharge Coefficient of Rectangular Broad-Crested Weir by CFD." In The 2nd International Conference of Buildings, Construction and Environmental Engineering (BCEE2-2015), Beirut, October 17-18: 123-7.

[9] Al-Hashimi, S. A., Madhloom, H. M, Nahi, T. N., and Al-Ansari, N. 2016. "Channel Slope Effect on Energy Dissipation of Flow over Broad Crested Weirs." Engineering 8 (12). Accessed November 8, 2017. https://doi.org/10.4236/eng.2016.812076.

[10] Liu, C., Hute, A., and Wenju, M. 2002. "Numerical and Experimental Investigation of Flow over a Semicircular
Weir." Acta Mechanics Sinica 18: 594-602.

[11] Wilcox, D. C. 1993. Turbulence Modeling for CFD. La Canada Flintridge: DCW Industries Inc.

[12] Launder, B., and Spalding, B. D. 1974. "The Numerical Computation of Turbulent Flow." Computer Methods in Applied Mechanics and Engineering 3: 269-89. Accessed November 8, 2017. https://doi.org/10.1016/0045-7825(74) $90029-2$.

[13] Hirt, C. W., and Nichols, B. D. 1981. "Volume of Fluid (VOF) Method for the Dynamics of Free Boundaries." Journal of Computational Physics 39: 201-25. Accessed November 8, 2015. https://doi.org/10.1016/0021-9991(81) 90145-5.

[14] Willmott, C. J., and Matsuura, K. 2005. "Advantages of the Mean Absolute Error (MAE) over the Root Mean Square Error (RMSE) in Assessing Average Model Performance." Climate Research 30: 79-82. 